\title{
A presumed extragonadal germ cell tumor that turned out to be a gastric cancer-a case report
}

\author{
Mona Kafka ${ }^{1}$, Ewald Wöll ${ }^{2}$, Thomas Brunhuber ${ }^{3}$, Leonhard Gruber ${ }^{4}$, Gennadi Tulchiner ${ }^{1}$, \\ Nina Staudacher ${ }^{1}$, Wolfgang Horninger ${ }^{1}$, Renate Pichler ${ }^{1}$ \\ ${ }^{1}$ Department of Urology, Medical University of Innsbruck, Innsbruck, Austria; ${ }^{2}$ Department of Internal Medicine, St. Vinzenz Hospital, Zams, \\ Austria; ${ }^{3}$ Laboratory of Pathology, Dr. Obrist and Dr. Brunhuber OG, Zams, Austria; ${ }^{4}$ Department of Radiology, Medical University of Innsbruck, \\ Innsbruck, Austria \\ Correspondence to: Renate Pichler, MD, PhD. Department of Urology, Medical University of Innsbruck, Anichstreet 35, A-6020 Innsbruck, Austria. \\ Email: Renate.Pichler@i-med.ac.at.
}

\begin{abstract}
A solely retroperitoneal mass in males in combination with elevated serum Alpha-Fetoprotein (AFP) and beta-human choriogonadotropin ( $\beta-\mathrm{HCG}$ ) levels is highly indicative of a metastatic testicular cancer. Although testicular cancers are rare, they represent the most common diagnosed cancer in males between 14 and 40 years. However, in cases without evidence of a primary testicular tumor, the rare diagnosis of a retroperitoneal extragonadal germ cell tumor (EGCT) must be assumed. Here, we describe the first published case of a 66-year-old man presenting with this typical clinical picture and the diagnosis of an AFP and $\beta$-HCG producing advanced gastric cancer with retroperitoneal lymph node metastases mimicking a primary retroperitoneal EGCT. The final diagnosis was only made by gastroscopy performed after a CT-guided retroperitoneal lymph node biopsy revealed an adenocarcinoma, suggesting an upper gastrointestinal tract primary origin. However, a specific initial anamnesis and also in the primary staging, including a full-body CT-scan there was no hint for another primary tumor. Only the slightly unusual extension of the retroperitoneal mass up to the ligamentum hepatoduodenale and the pylorus, as well as the atypical age made us question our initial diagnosis. This extraordinary case is of special clinical interest to all practising physicians and once again highlights the importance of keeping rare differential diagnosis such as AFP-producing gastrointestinal tumors in mind.
\end{abstract}

Keywords: Germ cell tumor; gastric cancer; Alpha-Fetoprotein (AFP); beta-human choriogonadotropin ( $\beta$-HCG)

Submitted Feb 19, 2021. Accepted for publication Apr 12, 2021.

doi: $10.21037 /$ tau-21-150

View this article at: http://dx.doi.org/10.21037/tau-21-150

\section{Introduction}

Testicular cancer is a rare neoplasm and represents only $1 \%$ of all malignancies occurring in males, yet is the most commonly diagnosed cancer in males aged 15 to 40 years (1). Peak incidences for diagnosis of a testicular cancer are the third decade of life with mainly non-seminoma or mixed germ-cell-tumors and around the fourth decade with generally pure seminomas (2). Usually, unilateral scrotal mass is the typical symptom of testicular cancer detected mostly by self-examination, or as an incidental ultrasound finding. Whereas more than $70 \%$ of patients with a non- seminomatous germ cell tumor (NSGCT) present with elevated serum tumor markers of either Alpha-Fetoprotein (AFP) or beta-human choriogonadotropin ( $\beta-\mathrm{HCG}$ ), only $30 \%$ of pure seminomas are $\beta$-HCG positive $(3,4)$. The retroperitoneal region is the typical primary stage of metastasis hence a contrast enhanced whole-body computed tomography (CT) scan is the gold standard imaging tool for staging (2).

Primary extragonadal germ cell tumors (EGCTs) are a rarity and only seen in $2-5 \%$ of all testicular cancer patients (5). Trama et al. recently conducted a large retrospective analysis evaluating the current incidence of 
Table 1 Differential diagnosis: Differential diagnosis of disease associated with elevated AFP and beta-HCG serum markers

\begin{tabular}{lll}
\hline Diagnosis & AFP $\uparrow$ & Beta-HCG $\uparrow$ \\
\hline Malignant & Hepatocellular carcinoma & Germ cell cancers \\
& Germ cell cancers & Gestational trophoblastic disease \\
& Ovarian cancers & Rarely gastrointestinal cancers \\
& Gastric cancers & \\
& Biliary cancers & \\
& Pancreatic cancers & \\
Benign & Liver cirrhosis & Hypogonadal states \\
& Hepatitis & Marijuana use \\
& Pregnancy & Pregnancy \\
\hline
\end{tabular}

AFP, Alpha-Fetoprotein; $\beta$-HCG, beta-human choriogonadotropin.

EGCTs in Europe and found an annual incidence rate of only $1.27 / 1,000,000$ with a 5 -year survival rate of $71 \%$ (6). EGCTs originate from neoplastic germ cells in extragonadal localisations and represent without evidence of a primary testicular cancer (5). Although the clear pathophysiological mechanism behind the development of EGCT is not fully understood yet, the two most widely accepted hypotheses are a malignant transformation of (I) displaced primordial germ cells during midline migration of the body and (II) persisting pluripotent cells in various organs (7). The question whether this special tumor is "truly" extragonadal or may present a secondary EGCT following a burned-out testicular tumor is difficult to answer. However, EGCTs with retroperitoneal localization are more often associated with a burned-out tumor compared to mediastinal EGCTs $(8,9)$. In cases with fibrous testicular scarring seen on ultrasound, the possibility of a burned-out tumor should always be considered (10).

EGCTs show a typical clinical presentation as masses localized along the midline of the body, predominantly in the anterior mediastinum (50-70\%) or the retroperitoneum $(30-40 \%)(11,12)$. As EGCTs demonstrate the same histopathological subtypes as gonadal germ cell neoplasms, $\mathrm{AFP}$ and $\beta$-HCG are the tumor markers of interest $(10,13)$. Consequently, an isolated retroperitoneal mass in males with negative testicular ultrasound is highly suspicious for an EGCT also based on the small number of potential differential diagnosis, such as lymphomas or retroperitoneal soft-tissue sarcomas (14). In case with further elevated tumor markers, the diagnosis of an EGCT seems to be obvious. However, extremely rare subtypes of gastrointestinal tumors also produces AFP and can mimic an EGCT (Table 1) (15). These AFP-secreting gastrointestinal tumors are characterized by an aggressive biological behaviour, high metastatic potential and poor prognosis $(16,17)$.

We present the first report describing an AFP- and HCG producing, retroperitoneally metastasized gastric adenocarcinoma mimicking a primary retroperitoneal EGCT. We present the following article in accordance with the CARE reporting checklist (available at http://dx.doi. org/10.21037/tau-21-150).

\section{Case presentation}

A 66-year-old man presented with enlarged retroperitoneal lymph nodes (up to $2.4 \mathrm{~cm}$ of short axis diameter) and elevated AFP (42.2 $\mu \mathrm{G} / \mathrm{L}), \beta$-HCG (167.6 U/L) and normal value of lactatdehydrogenase (LDH $168 \mathrm{U} / \mathrm{L})$. Detailed anamnesis yield a negative family history for tumors, no pre-existing conditions or previous medical interventions. As no abnormalities were found on testicular ultrasound, an EGCT was assumed. However, patient's age and the distribution of the lymphadenopathy atypical for a testicular cancer with significant non-midline affection (up to the ligamentum hepatoduodenale and the pylorus) made us question the initial diagnosis (Figure 1). Therefore, a CTguided retroperitoneal lymph node as well as a testicular biopsy were performed.

The histological result of the testicular biopsy was inconspicuous. Interestingly, the final pathological report on the retroperitoneal lymph nodes revealed metastasis 


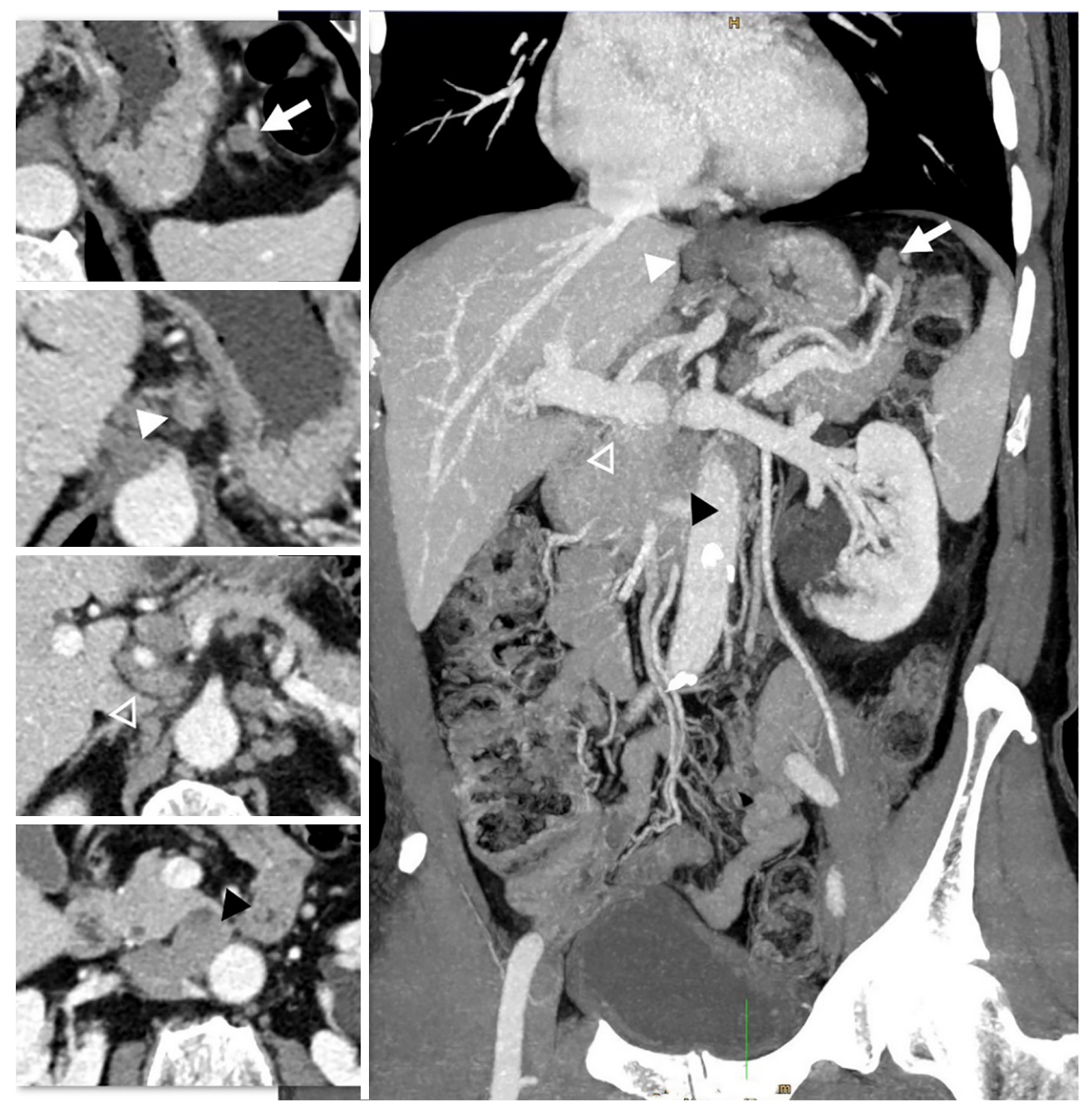

Figure 1 Representative CT-images of the metastatic expansion. Illustration of lymph node metastases distribution in computed tomography in coronal plane (maximum intensity projection reformatted main image, right) and corresponding axial planes (left): along the greater (white arrows) and lesser gastric curvature (white arrowheads), portal vein (empty arrowheads) and aorta (black arrowheads).

of a poorly differentiated adenocarcinoma with an immunohistochemical marker profile (TTF- $1^{-} \mathrm{CK} 7^{+} \mathrm{CK} 20^{+}$) suspicious for gastrointestinal cancer. Notably, there was no hint for a gastrointestinal cancer in the initial staging including a full-body CT-scan. Still, as the patient retrospectively reported he had suffered from epigastric pain with weight loss of $6 \mathrm{~kg}$ during the last 5 months, a gastroscopy was performed, revealing a locally advanced gastric cancer (Figure 2).

Histopathology confirmed a poorly differentiated mixed type gastric adenocarcinoma with trophoblastic tumor cell proliferations and the expression of $\beta-H C G$ and HER2/Neu (Figure 3). Subsequently, systemic therapy of the metastasized tumor with a triple combination using Capecitabine $\left(1,000 \mathrm{mg} / \mathrm{m}^{2}\right)$, Oxaliplatin $\left(85 \mathrm{mg} / \mathrm{m}^{2}\right)$ combined with Trastuzumab $(6 \mathrm{mg} / \mathrm{kg})$ was initiated. The first re-staging CT-scan after 3 cycles of treatment confirmed stable disease. Currently, the fifth chemotherapy cycle (of 6 planned) is ongoing. After the sixth cycle of chemotherapy, gastroscopy control with CT scan is scheduled followed by Trastuzumab maintenance. Up to now, no serious treatment-related adverse events occurred and the patient tolerates chemotherapy very well. This Case report was prepared in accordance to the Helsinki Declaration (as revised in 2013) and a written consent form was obtained by the patient and a positive ethical vote was 


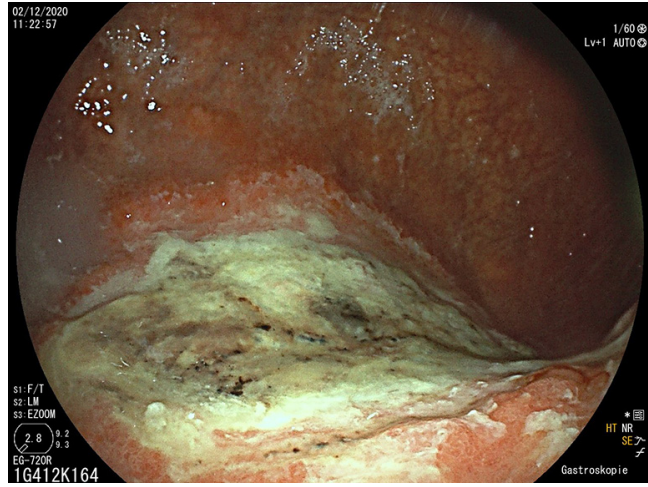

Figure 2 Endoscopic image. Representative endoscopic image of the gastroscopy confirming locally advanced gastric cancer.

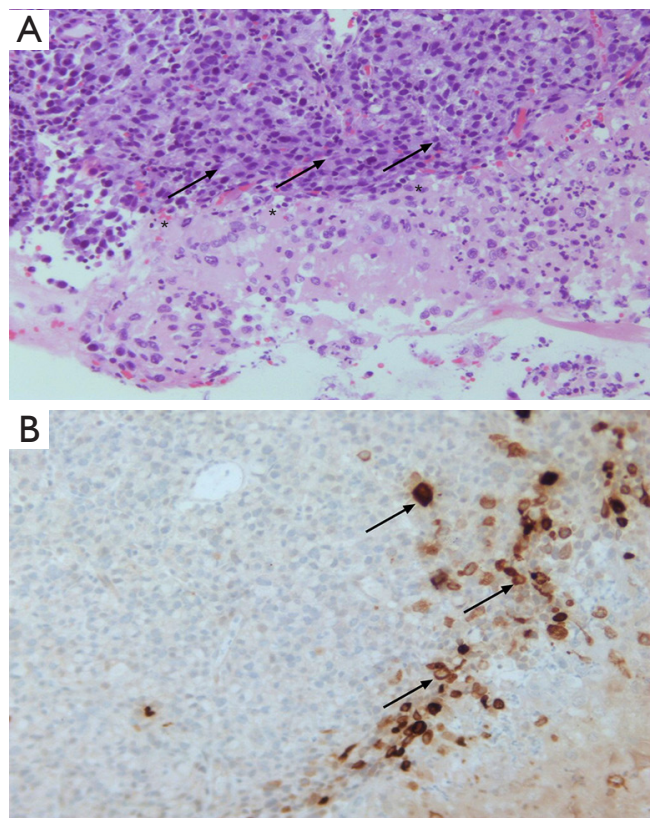

Figure 3 Histopathological picture. (A) Hematoxylin and eosin (HE) staining image demonstrating the gastric adenocarcinoma formation exhibiting high cellularity and densely packed, hyperchromatic nuclei (arrows), whereas the trophoblastic tumor cell component shows extensive cytoplasmatic staining with strong nuclear chromatin inhomogeneity $\left(^{*}\right)$. (B) Strong beta-human choriogonadotropin staining is observed in the trophoblastic tumor component (arrows) in contrast to conventional gastric adenocarcinomatoid tissue. The images are represented in a magnification level of $\times 200$. already approved (Ethical vote Number: 1017/2021).

\section{Discussion}

The clinical constellation of a men presenting with a retroperitoneal mass combined with elevated AFP and $\beta$-HCG is highly indicative of a metastatic testicular GCT. In light of missing evidence for a primary testicular cancer, the hypothesis of a primary EGCT was presumed. This was strengthened by the absence of clinical symptoms for another malignancy and only retroperitoneal lymphadenopathy on the initial whole-body CT-scan. Still, a somewhat peculiar lymph node localization deviating significantly from the midline, together with the presentation at a quite atypical age (66 years) for testicular cancer, made us question our initial diagnosis. Although it is known that gastric cancers tend to present with histological heterogeneous differentiations, this clinical picture represents an exceptional case $(17,18)$. AFP-secreting gastric cancer is an extremely rare subtype with unique clinicopathological features, high rates of lymphatic and liver metastasis with poor prognosis (18). The worldwide incidence of AFP-positive gastric cancer ranges only between $1.3 \%$ and $15 \%$ of all gastric cancers (19). AFP-positive gastric cancers can be classified into four subtypes including the hepatoid, yolk sac tumor, fetal gastrointestinal and mixed type (20). Currently, there is no specific treatment for these special subtype, thus following treatment concepts of common gastric cancer (21). However, preliminary data suggest that patients with AFPproducing gastric cancer and hepatoid adenocarcinoma of the stomach may benefit from PD-1 checkpoint inhibitor combined with chemotherapy (21). In our case, systemic therapy with Capecitabine, Oxaliplatin and Trastuzumab was initiated based on positive IHC expression of HER2/ Neu and $\beta$-HCG. A similar case with a HER2 and $\beta-H C G$ producing poorly differentiated gastric adenocarcinoma was described by Eivaz-Mohammadi et al. (22). Concerning $\beta$-HCG, elevated serum levels are much less frequently compared to AFP in gastric cancer, although a positive IHC staining of $\beta$-HCG can be found in up to $50 \%$ of patients with gastric cancer (23). Actually, measurable $\beta-\mathrm{HCG}$ serum level were only found in few individual cases, despite confirmed positive IHC staining for $\beta$-HCG (23-25). Knowledge on the exact pathophysiological mechanism of $\beta-\mathrm{HCG}$ 
production in gastric cancer is still lacking. However, in our case it might be assumed that $\beta-H C G$ secretion originates through the presence of trophoblastic cells. In cases without trophoblastic cells the hypothesis of dedifferentiation of the tumor leading to the secretion of $\beta-H C G$ is described in the literature (26). These findings show that $\beta-H C G$ is not a typical paraneoplastic hormone in gastric cancer with a large discrepancy of $\beta$-HCG analysis on tumor tissue and serum levels, thus being less suitable as biomarker in gastric cancer compared to AFP, CEA and CA19-9 (27). Moreover, the prognostic role of $\beta$-HCG positivity on IHC in gastric cancer remains still unclear $(26,28)$.

We highlight the first case of a gastric cancer with trophoblastic differentiation producing both AFP and $\beta-H C G$ with distinct retroperitoneal lymphadenopathy. The described clinical presentation nearly lead us to the initial misdiagnosis of a retroperitoneal EGCT. Therefore, this extraordinary case is of special clinical interest to demonstrate the importance of a precise diagnostic evaluation and to include rare differential diagnosis. Without histological verification, an unsuitable treatment strategy and a consequent poor clinical course may have resulted.

\section{Conclusions}

To our best knowledge, this is the first case of a gastric cancer secreting both AFP and $\beta$-HCG mimicking a testicular tumor. The clinical picture of a retroperitoneal mass combined with a negative testicular ultrasound and elevated testicular tumor markers is highly indicative of an EGCT. According to the current EAU guidelines (2), this constellation of findings alone would already justify the decision for chemotherapy according to the PEB (cisplatin, etoposide, bleomycin) regimen. Clearly, this extraordinary case is of special interest for all practicing physicians and highlights the importance of keeping rare differential diagnoses in mind.

\section{Acknowledgments}

Funding: None.

\section{Footnote}

Reporting Checklist: The authors have completed the CARE reporting checklist. Available at http://dx.doi.org/10.21037/ tau-21-150

Conflicts of Interest: All authors have completed the ICMJE uniform disclosure form (available at http://dx.doi. org/10.21037/tau-21-150). The authors have no conflicts of interest to declare.

Ethical Statement: The authors are accountable for all aspects of the work in ensuring that questions related to the accuracy or integrity of any part of the work are appropriately investigated and resolved. This Case report was prepared in accordance to the Helsinki Declaration (as revised in 2013) and a written consent form was obtained by the patient and a positive ethical vote was already approved (Ethical vote Number: 1017/2021).

Open Access Statement: This is an Open Access article distributed in accordance with the Creative Commons Attribution-NonCommercial-NoDerivs 4.0 International License (CC BY-NC-ND 4.0), which permits the noncommercial replication and distribution of the article with the strict proviso that no changes or edits are made and the original work is properly cited (including links to both the formal publication through the relevant DOI and the license). See: https://creativecommons.org/licenses/by-nc-nd/4.0/.

\section{References}

1. Park JS, Kim J, Elghiaty A, et al. Recent global trends in testicular cancer incidence and mortality. Medicine (Baltimore) 2018;97:e12390.

2. Albers P, Albrecht W, Algaba F, et al. Guidelines on Testicular Cancer: 2015 Update. Eur Urol 2015;68:1054-68.

3. Dieckmann K-P, Simonsen-Richter H, Kulejewski M, et al. Serum Tumour Markers in Testicular Germ Cell Tumours: Frequencies of Elevated Levels and Extents of Marker Elevation Are Significantly Associated with Clinical Parameters and with Response to Treatment. BioMed Res Int 2019;2019:5030349.

4. Gilligan TD, Seidenfeld J, Basch EM, et al. American Society of Clinical Oncology Clinical Practice Guideline on uses of serum tumor markers in adult males with germ cell tumors. J Clin Oncol 2010;28:3388-404.

5. Ronchi A, Cozzolino I, Montella M, et al. Extragonadal germ cell tumors: Not just a matter of location. A review about clinical, molecular and pathological features. Cancer Med 2019;8:6832-40.

6. Trama A, Mallone S, Nicolai N, et al. Burden of testicular, paratesticular and extragonadal germ cell tumours in Europe. Eur J Cancer 2012;48:159-69. 
7. Oosterhuis JW, Stoop H, Honecker F, et al. Why human extragonadal germ cell tumours occur in the midline of the body: old concepts, new perspectives. Int J Androl 2007;30:256-63; discussion 263-4.

8. Mikuz G. Germ cell and sex cord-stromal tumors of the testis: WHO classification 2016. Pathologe 2017;38:209-20.

9. Scholz M, Zehender M, Thalmann GN, et al. Extragonadal retroperitoneal germ cell tumor: evidence of origin in the testis. Ann Oncol 2002;13:121-4.

10. Williamson SR, Delahunt B, Magi-Galluzzi C, et al. The World Health Organization 2016 classification of testicular germ cell tumours: a review and update from the International Society of Urological Pathology Testis Consultation Panel. Histopathology 2017;70:335-46.

11. Albany C, Einhorn LH. Extragonadal germ cell tumors: clinical presentation and management. Curr Opin Oncol 2013;25:261-5.

12. Stang A, Trabert B, Wentzensen N, et al. Gonadal and extragonadal germ cell tumours in the United States, 1973-2007. Int J Androl 2012;35:616-25.

13. Busch J, Seidel C, Zengerling F. Male Extragonadal Germ Cell Tumors of the Adult. Oncol Res Treat 2016;39:140-4.

14. Shinagare AB, Jagannathan JP, Ramaiya NH, et al. Adult extragonadal germ cell tumors. AJR Am J Roentgenol 2010;195:W274-80.

15. Perkins GL, Slater ED, Sanders GK, et al. Serum Tumor Markers. Am Fam Physician 2003;68:1075-82.

16. Feng Y, Li Y, Dai W, et al. Clinicopathologic Features and Prognostic Factors in Alpha-Fetoprotein-Producing Colorectal Cancer: Analysis of 78 Cases. Cell Physiol Biochem 2018;51:2052-64.

17. Chun H, Kwon SJ. Clinicopathological characteristics of alpha-fetoprotein-producing gastric cancer. J Gastric Cancer 2011 Mar;11:23-30.

18. Liu X, Cheng Y, Sheng W, et al. Clinicopathologic features and prognostic factors in alpha-fetoprotein-producing gastric cancers: analysis of 104 cases. J Surg Oncol 2010

Cite this article as: Kafka M, Wöll E, Brunhuber T, Gruber L, Tulchiner G, Staudacher N, Horninger W, Pichler R. A presumed extragonadal germ cell tumor that turned out to be a gastric cancer-a case report. Transl Androl Urol 2021;10(6):2528-2533. doi: 10.21037/tau-21-150
Sep 1;102:249-55.

19. McIntire KR, Waldmann TA, Moertel CG, et al. Serum alpha-fetoprotein in patients with neoplasms of the gastrointestinal tract. Cancer Res 1975;35:991-6.

20. Li X, Shi F, Le M, et al. A study of histopathology and classification on AFP-positive gastric carcinoma. Chin J Clin Exp Pathol 1999;15:293-6.

21. Li W, Li Q, Yu Y, et al. Effect of Immune Checkpoint Inhibitors Plus Chemotherapy on Advanced Gastric Cancer Patients with Elevated Serum AFP or Hepatoid Adenocarcinoma. Cancer Manag Res 2020;12:11113-9.

22. Eivaz-Mohammadi S, Gonzalez-Ibarra F, Abdul W, et al. Her2 + and b-HCG Producing Undifferentiated Gastric Adenocarcinoma. Case Rep Med 2014;2014:268919.

23. Rau B, Below C, Haensch W, et al. Significance of serum beta-hCG as a tumor marker for stomach carcinoma. Langenbecks Arch Chir 1995;380:359-64.

24. Ben Kridis W, Ben Hassena R, Charfi S, et al. Gastric signet-ring cell carcinoma with hypersecretion of $\beta$-Human chorionic gonadotropin and review of the literature. Exp. Oncol 2018;40:149-151.

25. Arai O, Kakutani A, Mouri H, et al. A case of advanced gastric cancer growing extramurally with gynecomastia and high hCG-beta serum level. Gan To Kagaku Ryoho 2010;37:1369-72.

26. Yakeishi Y, Mori M, Enjoji M. Distribution of $\beta$-human chorionic gonadotropin-positive cells in noncancerous gastric mucosa and in malignant gastric tumors. Cancer 1990;66:695-701.

27. Ghaderi B, Moghbel H, Daneshkhah N, et al. Clinical Evaluation of Serum Tumor Markers in the Diagnosis of Gastric Adenocarcinoma Staging and Grading. J Gastrointest Cancer 2019;50:525-9.

28. Webb A, Scott-Mackie P, Cunningham D, et al. The prognostic value of serum and immunohistochemical tumour markers in advanced gastric cancer. Eur J Cancer 1996;32A:63-8. 